\title{
Agora entrou água!
}

\section{Taking on water}

\author{
Dárnisson Viana Silva ${ }^{1}$
}

Este ensaio fotográfico foi gestado em longo período de campo em meio a um pequeno povoado de pescadores (as) que beira o rio Tapajós, no estado do Pará, Amazônia, Brasil. Trata-se, sem dúvida, de um vestígio material (não só) ${ }^{2}$ de minha de pesquisa de doutorado sobre saberes tradicionais e regimes de informações entre pescadores artesanais ribeirinhos inseridos em contextos urbanos numa cidade amazônica. O mote escolhido para a linguagem visual aqui empregada favorece, entre outros aspectos, uma leitura socioantropológica de práticas que correspondem certa conversão das "artimanhas de capturar o peixe" - de suma importância no universo da análise - para uma "artimanha do viver", - imprescindível para compor outras interpretações ${ }^{3}$. Temos visto, com certa freqüência, populações ditas tradicionais inseridas em contextos de conflito territorial com seguimentos empresariais das mais diferentes matizes e, em maior número, no caso amazônico, as consideradas provedoras de commodities nos mercados nacionais e internacionais (SILVA, 1997; LOUREIRO, 2009; ALMEIDA, 2012) bem como aquelas vinculadas a grandes construtoras. Entretanto, a narrativa imagética que se segue e que procuramos expor neste espaço não se concentra em explicitar este último processo, mas sim no que está prestes a desaparecer caso o afã do lucro não cesse sobre o território em disputa. O colapso de uma sociedade de pesca que alimenta e é alimentada ${ }^{4}$ pela Sub-bacia hidrográfica do lago do Juá, localizada no município de San-

\footnotetext{
${ }^{1}$ Doutorando em Ciências Sociais pela Universidade Federal de Campina Grande/PB. Mestre em Antropologia pela Universidade Federal da Paraíba e graduado em Ciências Sociais pela Universidade Estadual Paulista - Marília/SP. Integrante do Laboratório de Estudos sobre Tradições (LETRA - UFCG - CNPq).

${ }^{2}$ Estamos cientes da renovação das discussões em torno do uso da imagem para ampliar a compreensão dos processos de simbolização próprios dos universos culturais com os quais antropólogos se defrontam em suas pesquisas de campo. Mesmo sujeita às convenções de representação culturalmente construídas e, portanto, orientadas. Compactuamos com a perspectiva de que "a imagem pode e deve ser utilizada como uma narrativa visual que informa o relato etnográfico com a mesma autoridade do texto escrito. Mais do que representar fatos visíveis, tais imagens acrescentam outros meios de representação à descrição etnográfica" (BITTENCOURT, 1998, p. 199).

${ }^{3} \mathrm{Em}$ texto recente publicado pela Revista Amazônica tentamos explorar estas reflexões a partir de uma família de pescadores residentes numa vila balneária conhecida de Santarém, Alter do Chão, ao interrogar em que medida as "artimanhas" de capturar o peixe em um território fortemente marcado pelo turismo global pode se converter numa "artimanha do viver" em contextos polivalentes e multilocalizados. A referência encontra-se na bibliografia.

${ }^{4}$ Estamos dando especial atenção à perspectiva que, de uma forma inovadora, considera que a própria
} 
tarém/PA, não é tão somente um alarde ambientalista, mas uma realidade lamentável, lamentavelmente tangível. Apesar dos esforços somados da sociedade civil organizada e dos ministérios públicos (MPF/MPE) em conter as investidas do comércio imobiliário nas redondezas da área atingida parece não surtir efeito diante das ações de alguns atores sociais e suas alianças políticas locais.

Contudo, no contraponto daqueles que tentam invisibilizar as famílias que ali dão sentido às suas vidas, temos aqui (por ocasião das limitações) um curto registro de um universo muito maior do saber e da cultura local dos pescadores (as) do Lago do Juá. Convidamos aos "leitores de imagens" especialistas e não-especialistas a serem "tradutores", através e por meio do "outro" representado na instantânea.

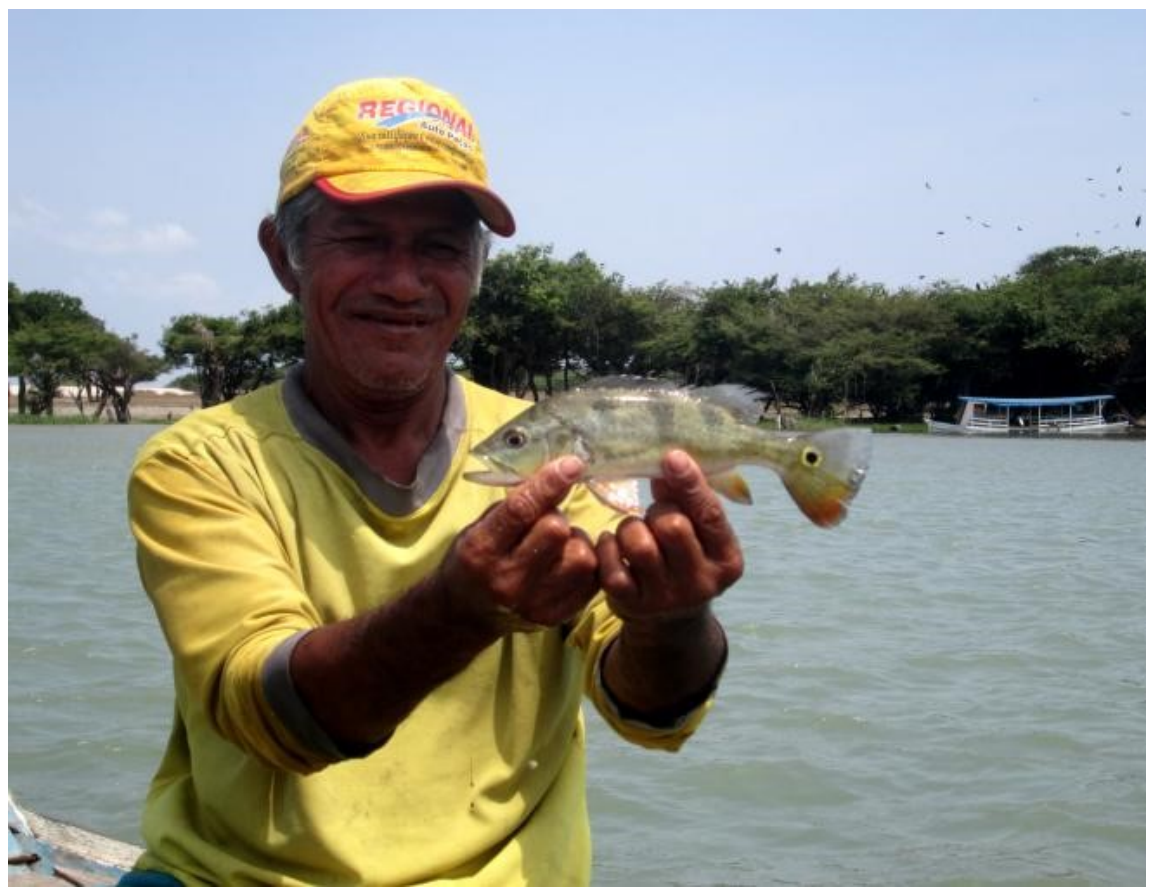

viabilidade dos recursos naturais a partir de uma relação mútua, igualmente, depende da existência de comunidades viáveis em torno de determinados ecossistemas (MANESCHY, 2010, comunicação oral). 


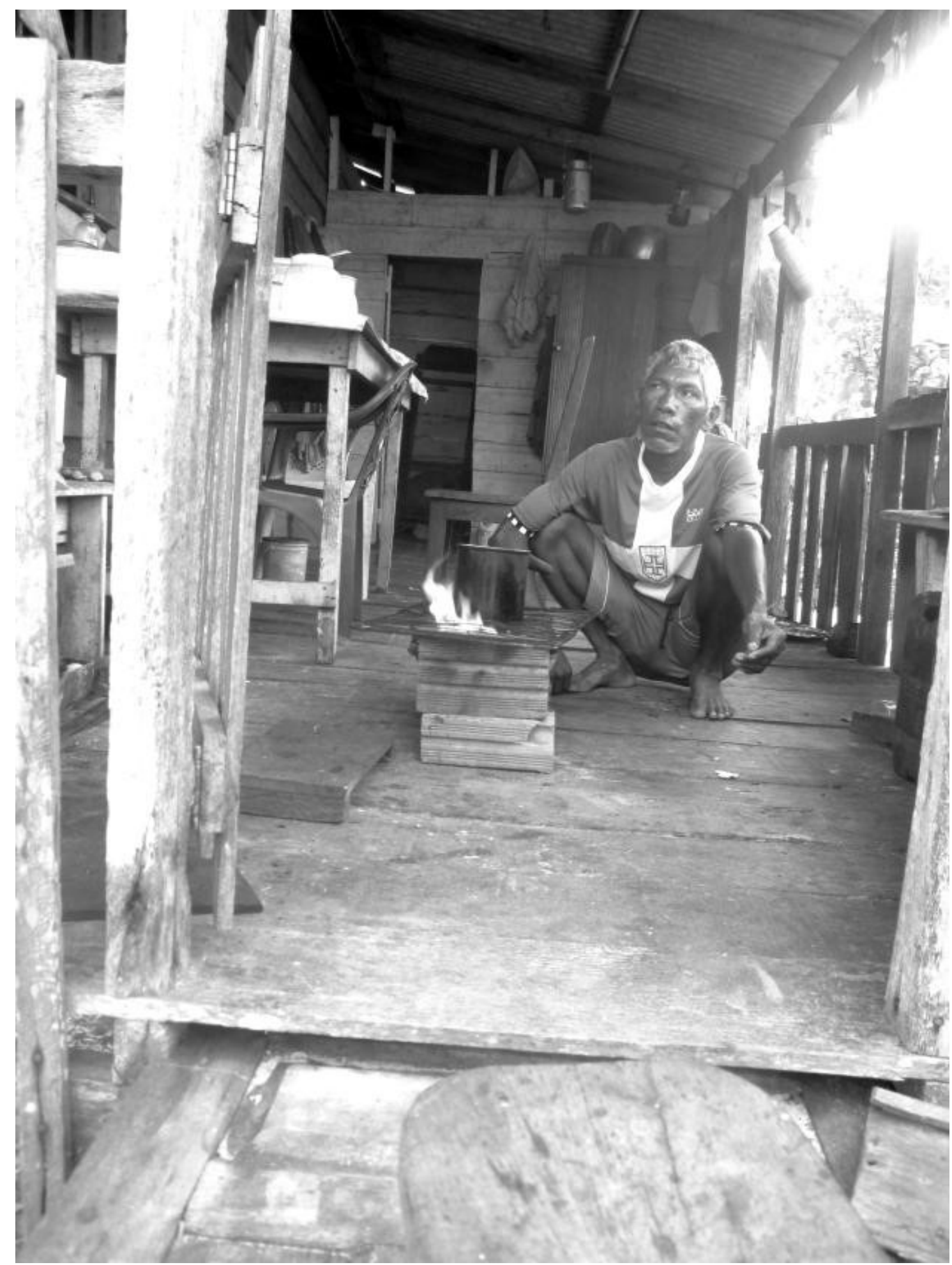




\section{Revista Ciências da Soci}
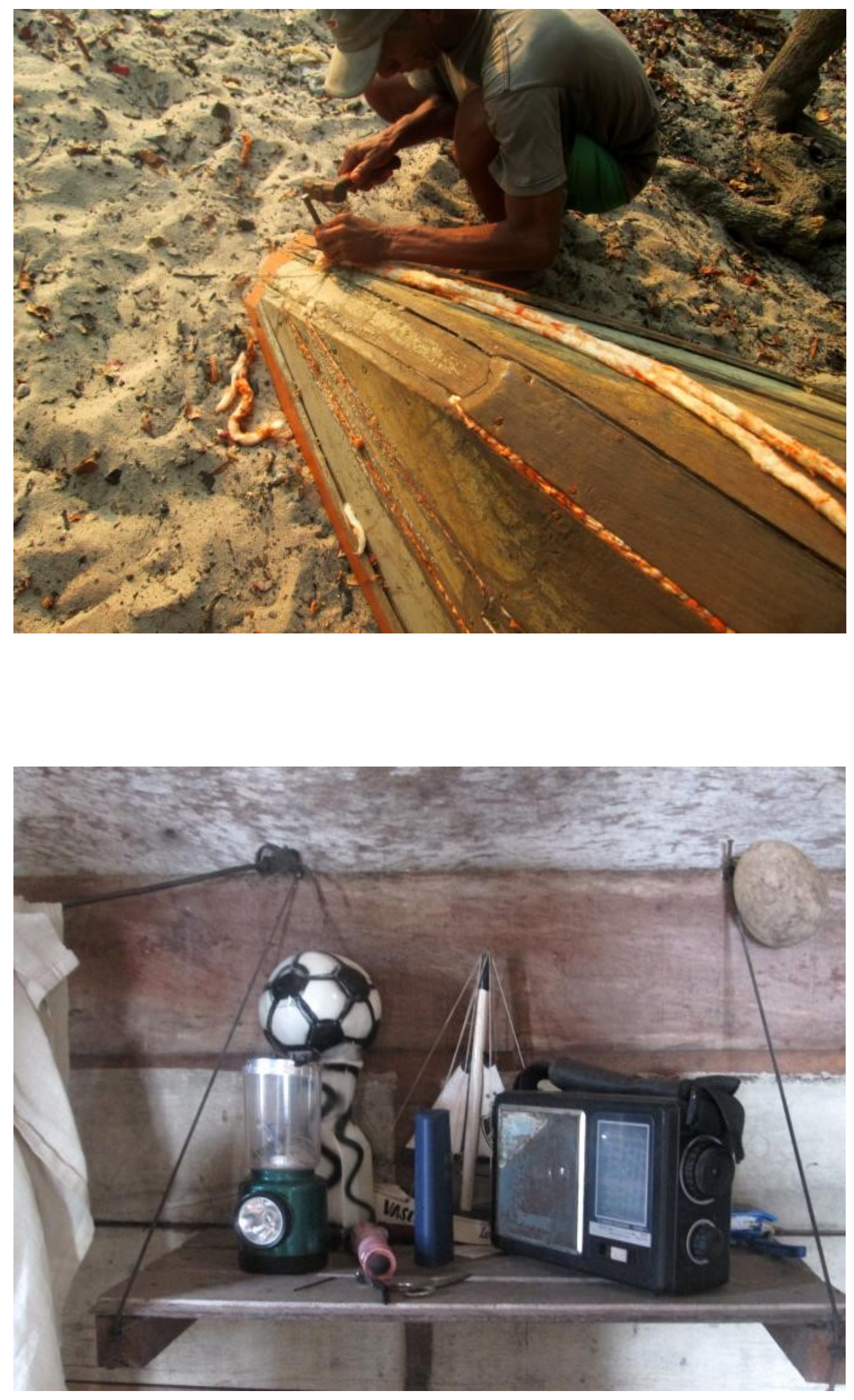

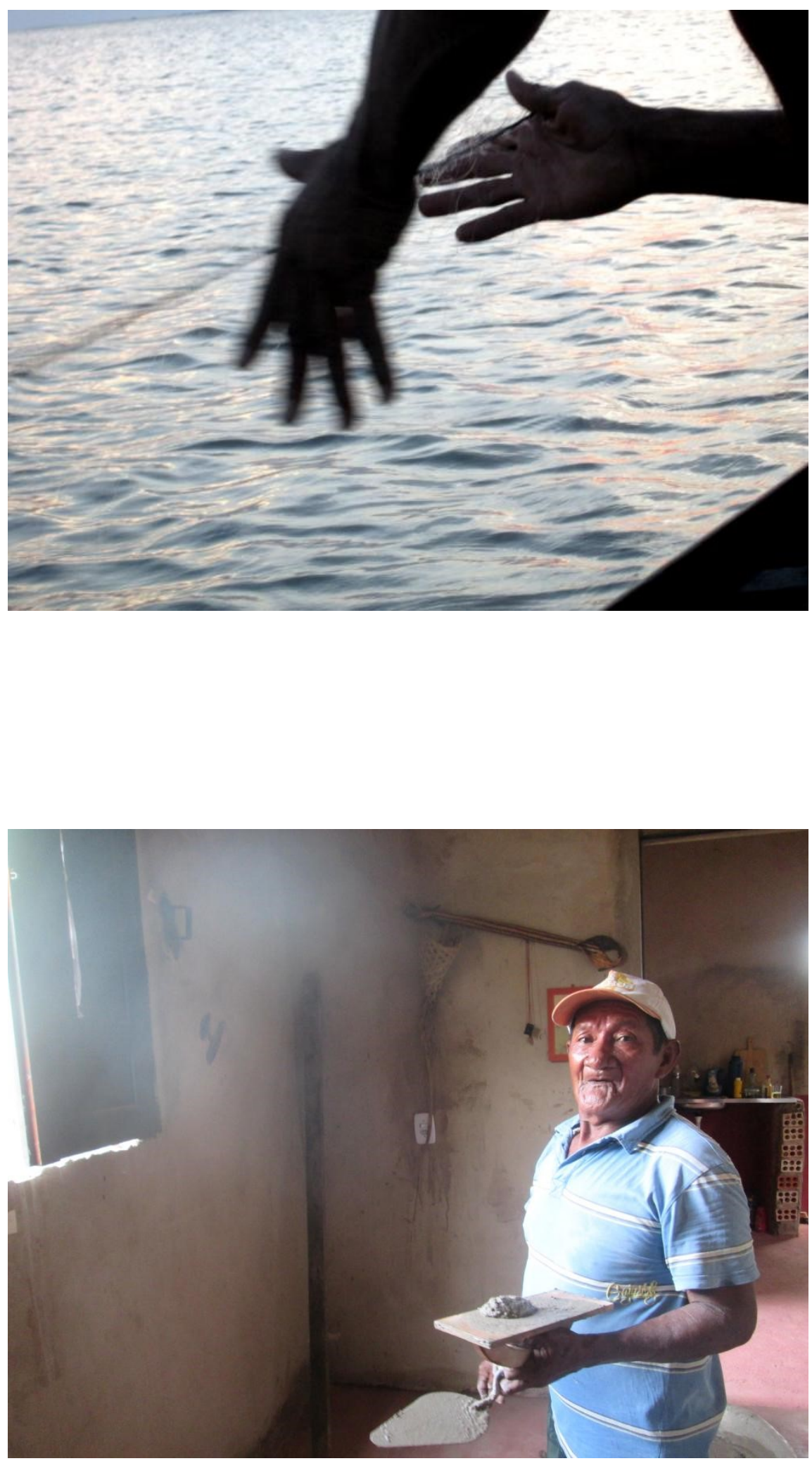

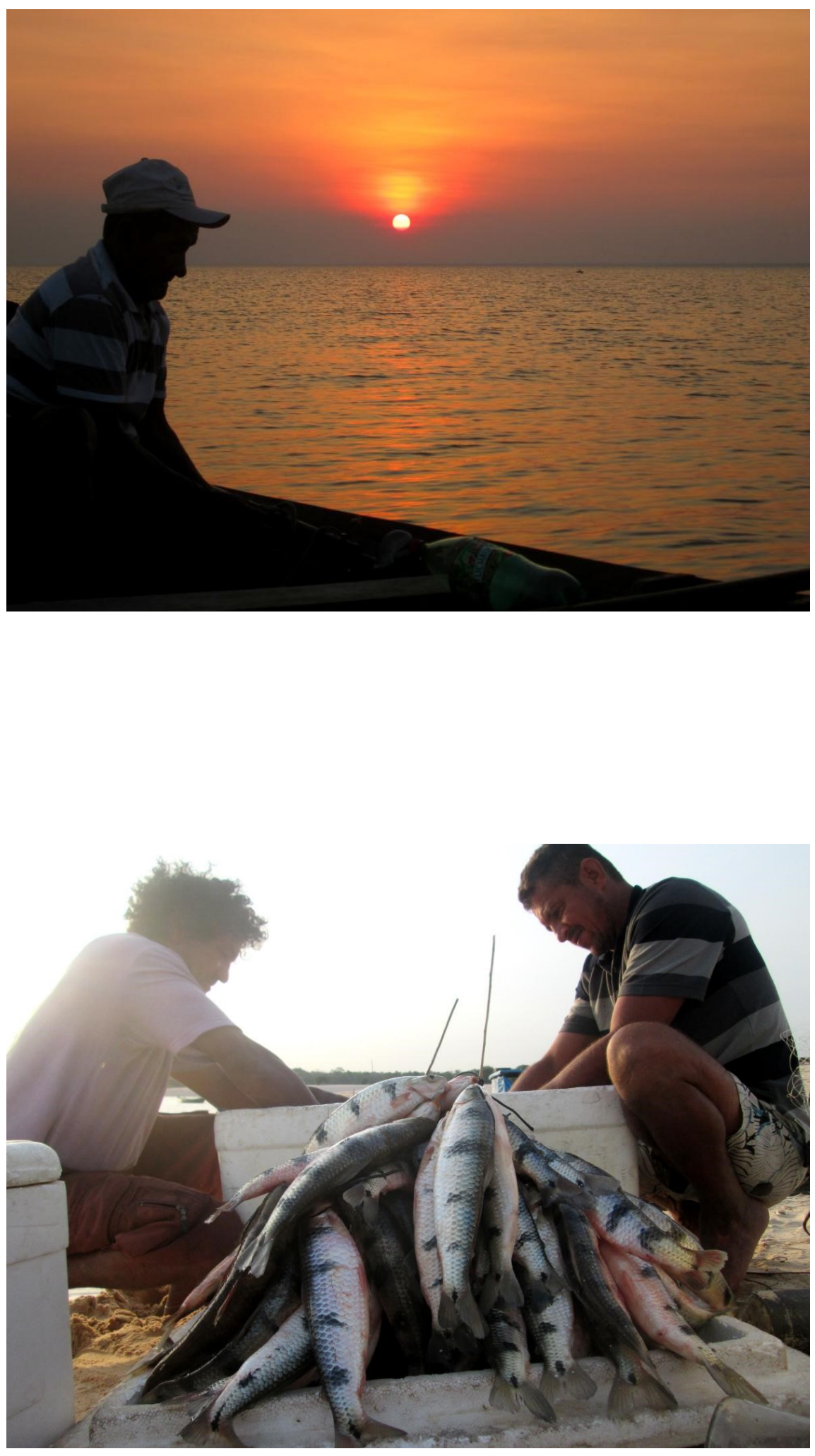

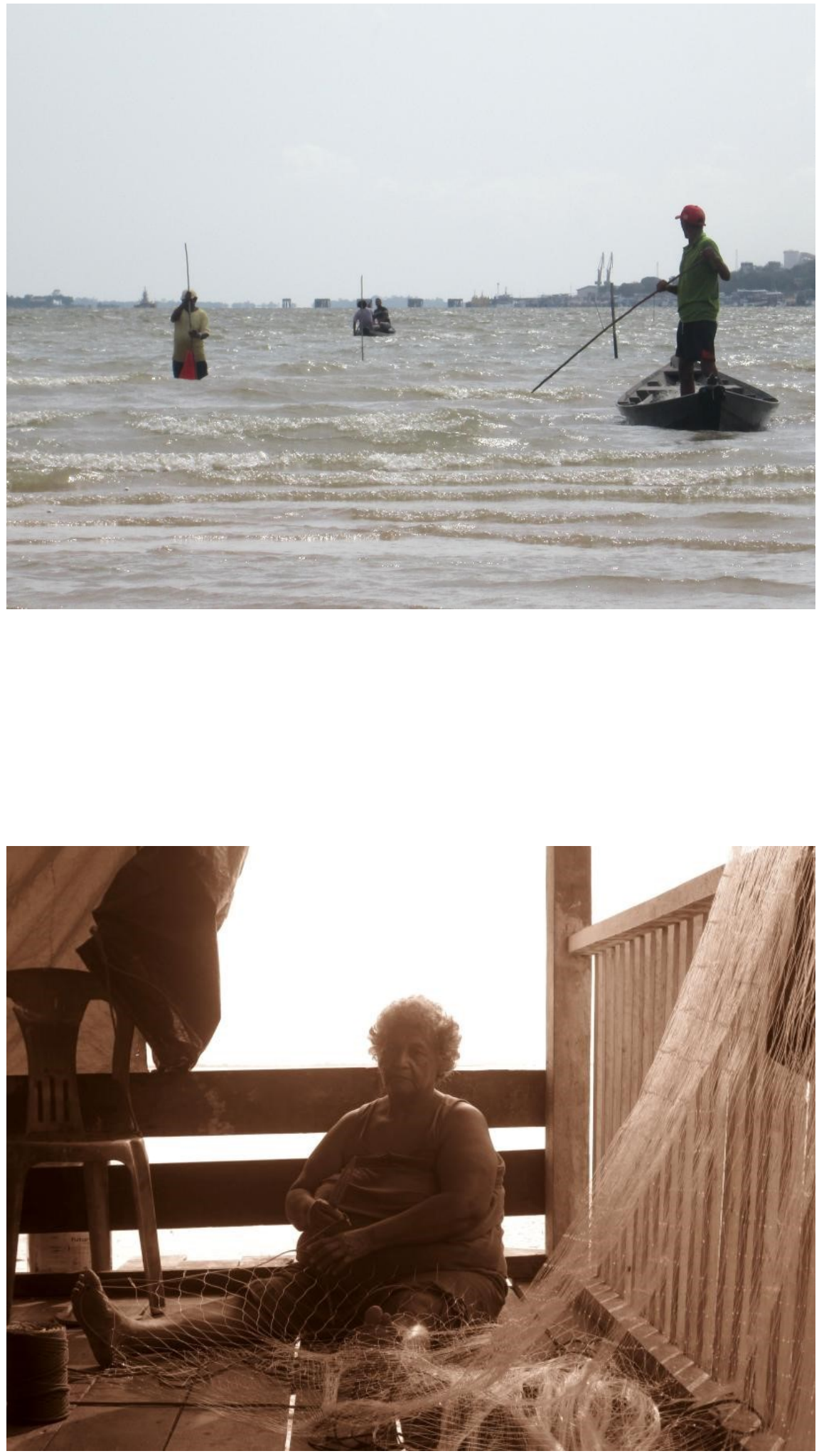


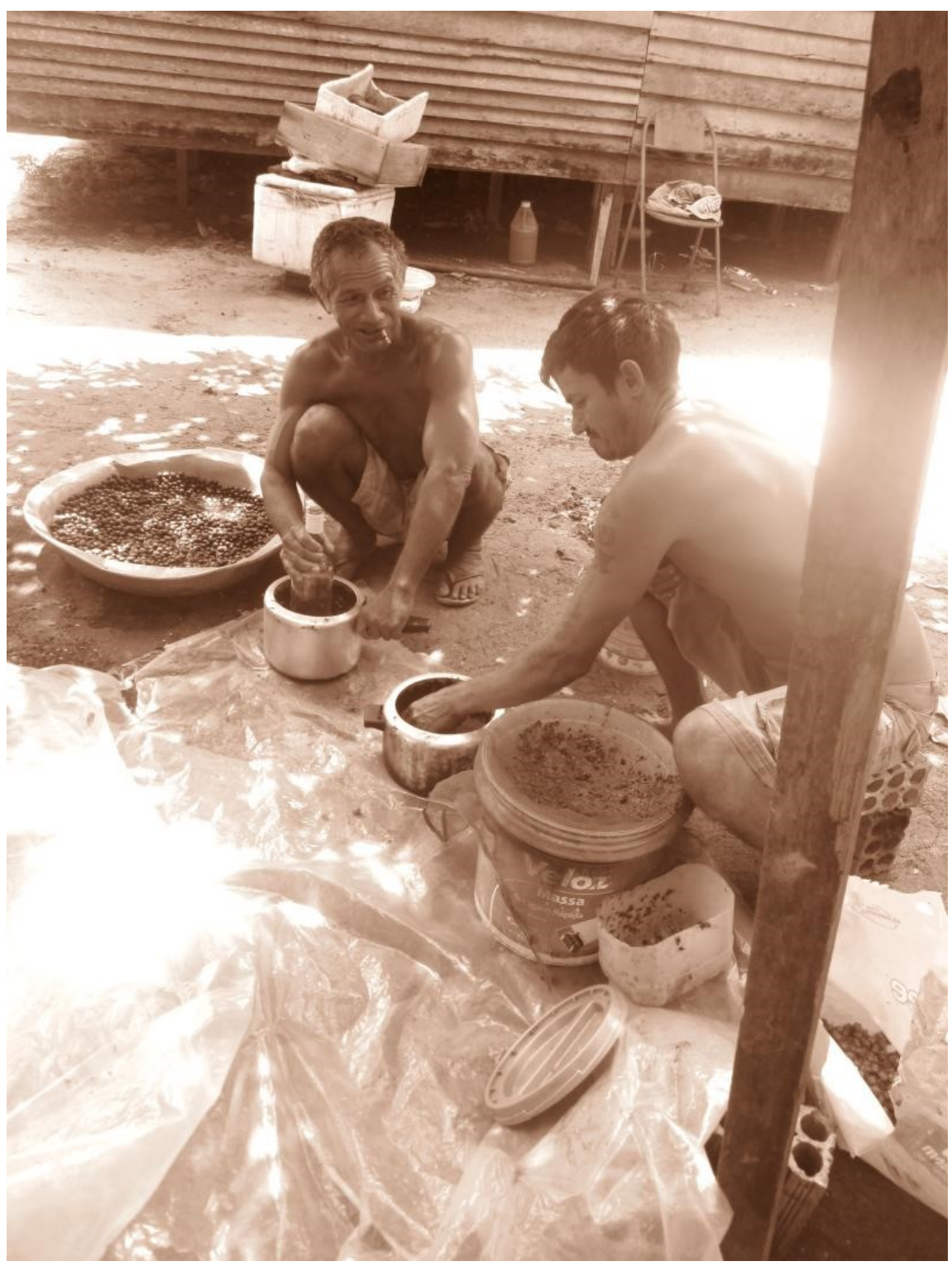



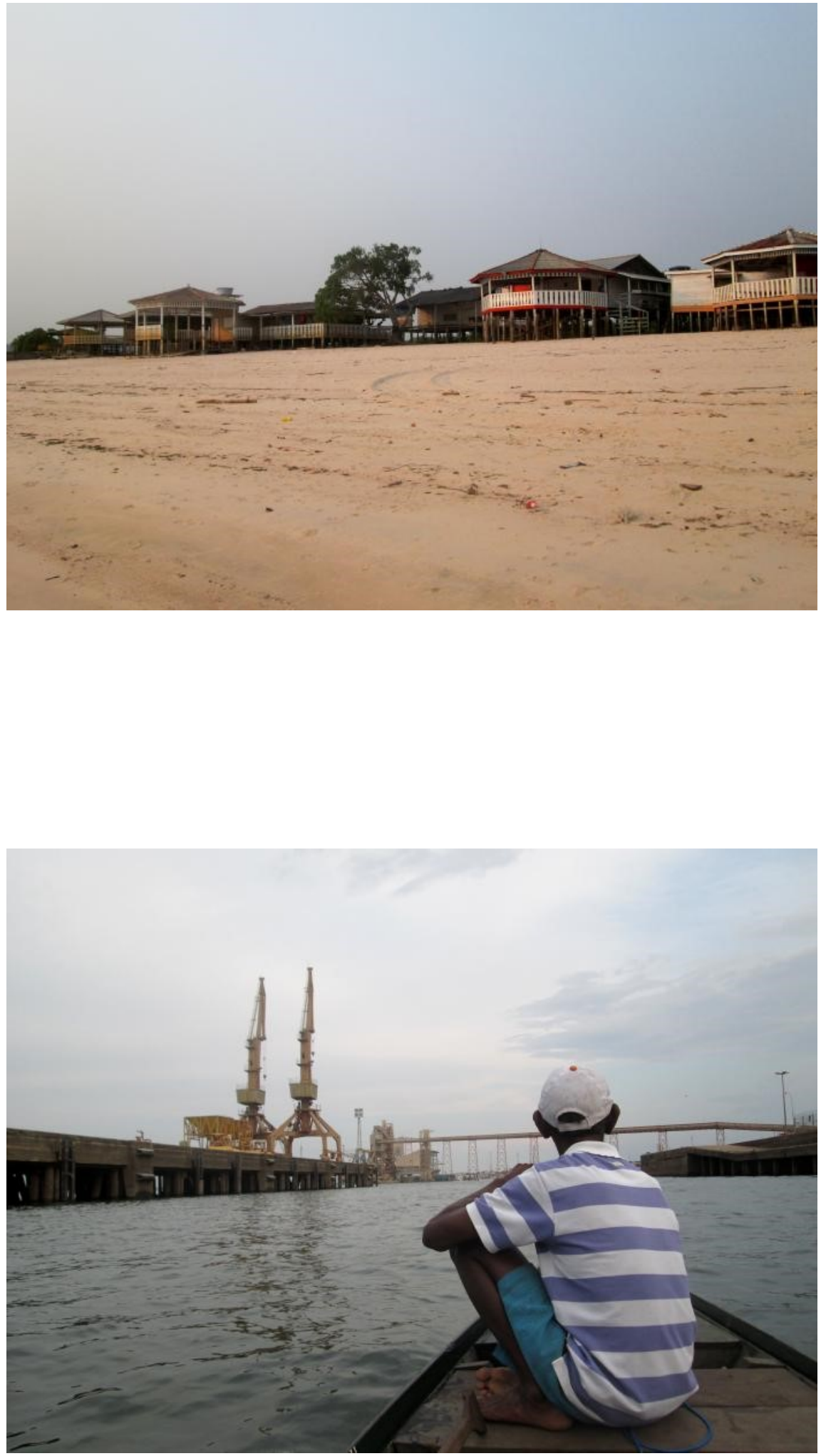

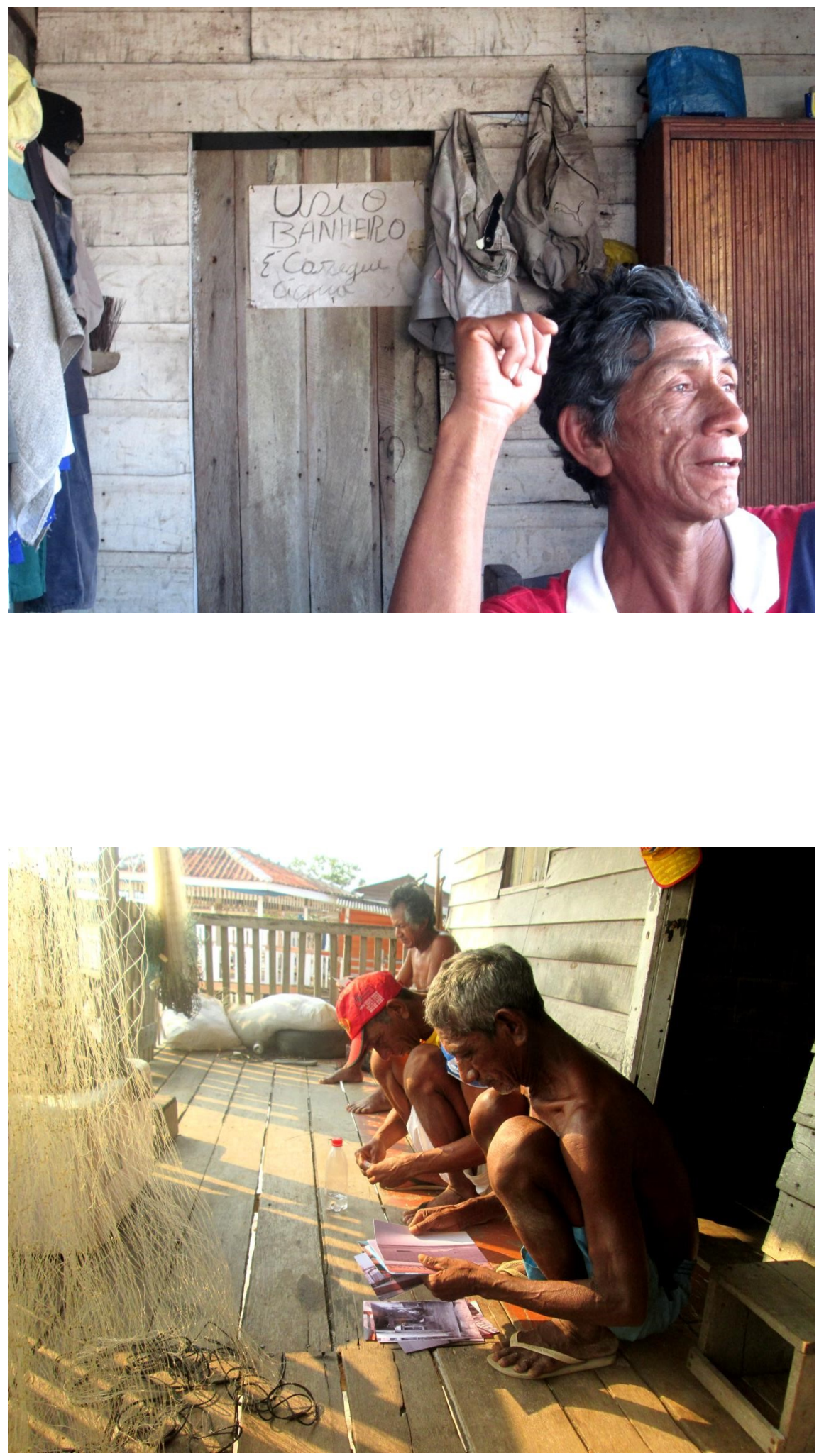


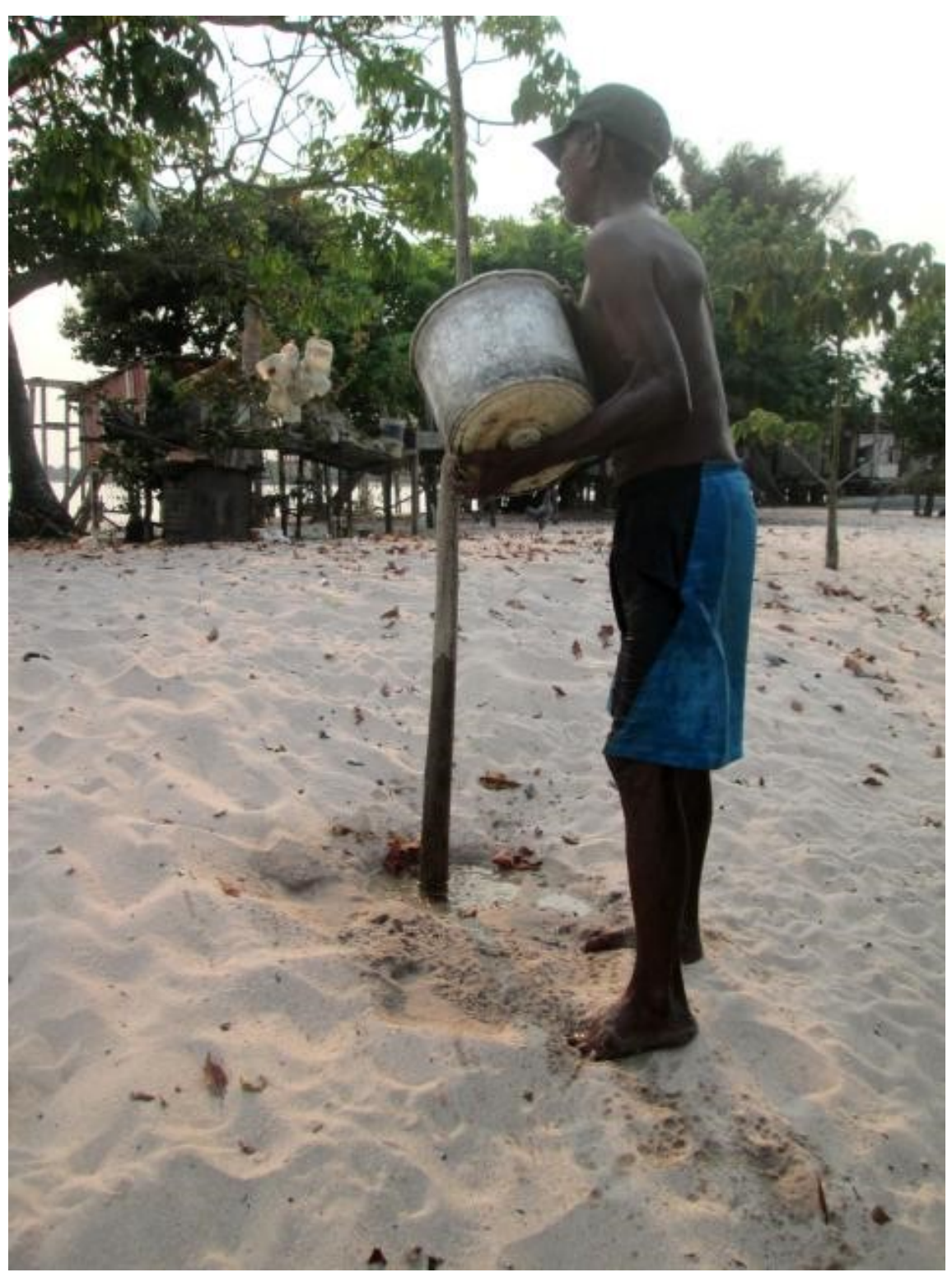




\section{Referências}

ALMEIDA, Alfredo Wagner Berno de. Territórios e territorialidades específicas na Amazônia: entre a "proteção" e o "protecionismo". Caderno CRH (UFBA. Impresso), v. 25, p. 63-71, 2012.

BITTENCOURT, Luciana Aguiar. Algumas considerações sobre o uso da imagem fotográfica na pesquisa antropológica. In: FELDMAN-BIANCO, Bela; LEITE, Mirian L.

Moreira (orgs.). Desafios da Imagem: fotografia, iconografia e vídeo nas ciências sociais. Campinas, SP: Papirus, 1998.

LOUREIRO, Violeta R. A Amazônia no século XXI - novas formas de desenvolvimento. São Paulo: Editora Empório do Livro, 2009.

SILVA, Darnisson Viana. "AGORA ENTROU ÁGUA": sobre experiência e estratégias de sobrevivência entre pescadores artesanais em uma vila amazônica. Amazônica, Rev. Antropol. (Online) 9 (1): 180 - 207, 2017.

SILVA, Marilene Corrêa da. Metamorfoses da Amazônia. Tese de Doutorado - Programa de Pós-Graduação em Ciências Sociais. Instituto de Filosofia e Ciências Humanas Universidade Estadual de Campinas: Campinas/SP, 1997.

\section{Outras Fontes}

MANESCHY, Maria Cristina Alves. I Colóquio Nacional Coletividades Locais Cultura e Natureza. DVD 2 - Coletividades locais e uso de recursos naturais NUMA - PPGEDAM - UFPA, 2010. Disponível em: <https://www.youtube.com/watch?v=ifK9OiPctql>. Acesso em: 06 de abr. 2018. 